\title{
Method for Measuring Cooling Efficiency of Water Droplets Impinging onto Hot Metal Discs
}

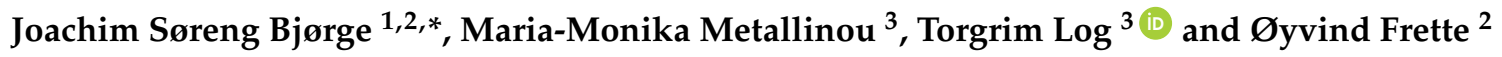 \\ Q Rådgivning AS/PDS Protek, Øvregata 126, 5527 Haugesund, Norway \\ Department of Physics and Technology, University of Bergen, 5020 Bergen, Norway; oyvind.frette@uib.no \\ 3 Faculty of Engineering and Science, Western Norway University of Applied Sciences, 5528 Haugesund, \\ Norway; monika.metallinou@hvl.no (M.-M.M.); torgrim.log@hvl.no (T.L.) \\ * Correspondence: jsb@q-rad.no; Tel.: +47-9098-1051
}

Received: 18 May 2018; Accepted: 7 June 2018; Published: 9 June 2018

\begin{abstract}
The present work outlines a method for measuring the cooling efficiency of droplets impinging onto hot metal discs in the temperature range of $85^{\circ} \mathrm{C}$ to $400{ }^{\circ} \mathrm{C}$, i.e., covering the boiling regimes experienced when applying water to heated objects in fires. Stainless steel and aluminum test discs (with 50-mm diameter, 10-mm thickness, and a surface roughness of Ra 0.4 or Ra 3) were suspended horizontally by four thermocouples that were used to record disc temperatures. The discs were heated by a laboratory burner prior to the experiments, and left to cool with and without applying 2.4-mm diameter water droplets to the discs while the disc temperatures were recorded. The droplets were generated by the acceleration of gravity from a hypodermic injection needle, and hit the disc center at a speed of $2.2 \mathrm{~m} / \mathrm{s}$ and a rate of $0.02 \mathrm{~g} / \mathrm{s}$, i.e., about three droplets per second. Based on the recorded rate of the temperature change, as well as disc mass and disc heat capacity, the absolute droplet cooling effect and the relative cooling efficiency relative to complete droplet evaporation were obtained. There were significant differences in the cooling efficiency as a function of temperature for the two metals investigated, but there was no statistically significant difference with respect to whether the surface roughness was Ra 0.4 or Ra 3. Aluminum showed a higher cooling efficiency in the temperature range of $110^{\circ} \mathrm{C}$ to $140{ }^{\circ} \mathrm{C}$, and a lower cooling efficiency in the temperature range of $180{ }^{\circ} \mathrm{C}$ to $300{ }^{\circ} \mathrm{C}$ compared to stainless steel. Both metals gave a maximum cooling efficiency in the range of $75 \%$ to $85 \%$. A minimum of $5 \%$ cooling efficiency was experienced for the aluminum disc at $235^{\circ} \mathrm{C}$, i.e., the observed Leidenfrost point. However, stainless steel did not give a clear minimum in cooling efficiency, which was about $12-14 \%$ for disc temperatures above $300{ }^{\circ} \mathrm{C}$. This simple and straightforward technique is well suited for assessing the cooling efficiency of water droplets impinging onto heated metal objects. The test rig also worked well for demonstrating droplet boiling regimes and water droplet cooling efficiency to fire safety engineering students.
\end{abstract}

Keywords: hot metals; water droplet cooling; heat transfer

\section{Introduction}

Evaporation processes are of interest in numerous areas such as agricultural [1], industrial [2], and academic [3] communities, as well as for individuals [4]. When evaporating at room temperature, the substrate material plays an important role in the evaporation process, as does the ambient air relative humidity [5]. However, the ambient air relative humidity is less important when droplets evaporate on substrates at elevated temperatures [6]. In a recent study of a wide range of water droplets sizes in the transition regime of a boiling crisis, Misyura [7] demonstrated that several material parameters are important when water droplets hit objects, wet the surface in different ways, and then start evaporating. Droplet contact angles play a role [8], and may depend on impurities, additives, etc. 
Additives may therefore be used to reduce surface tension and thus improve performance $[9,10]$. Some researchers have studied the behavior of different droplet parameters such as size, impinging velocity [11], wall material [12,13], temperature below the Leidenfrost point [14], and the influence of solid-liquid contact time [15]. A review concerning droplets impinging onto hot metals was conducted by Liang and Mudawar [16] for all of the involved boiling regimes for water droplets on metal surfaces. A literature review on the Leidenfrost temperature for water on different heated materials is given by Bernardin and Mudawar [17]. Water droplet cooling efficiency for droplets hitting Teflon-covered copper was recorded by Sawyer et al. [18], who reported a cooling efficiency in the range of $50 \%$ to $90 \%$ at temperatures up to the temperatures associated with a boiling crisis. However, no studies were identified as covering the whole range from below the boiling point and all the way into the film-boiling regime.

In the process industry, fire-exposed pressurized pipes and vessels may rupture violently and release their combustible or poisonous contents if weakened by overheating. Considerable resources are therefore used for designing and maintaining active fire protection systems, i.e., deluge systems, fire monitors, etc. The NORSOK standard S-001 [19] devotes multiple pages to active fire protection. For process areas, the design criteria is $10 \mathrm{~L} / \mathrm{min} \cdot \mathrm{m}^{2}$. However, studies of the performance of these systems are scarce, and would need to cover all of the involved boiling regimes. Full-scale experiments were performed by Kazemi [20] and Drange [21] in standardized $0.3 \mathrm{~kg} / \mathrm{s}$ jet fire scenarios. Deluge and fire monitors in large-scale jet fires were studied by Opstad [22]. None of these studies reported water droplet cooling efficiency.

The purpose of the present study was to develop a method for measuring the cooling efficiency of water droplets impinging onto hot stainless steel and aluminum in the temperature range of $80-400{ }^{\circ} \mathrm{C}$. This temperature range covers the different boiling regimes that are associated with water droplets on metal substrates. These water droplet boiling regimes are presented in Section 2. The apparatus that was developed for the study is presented in Section 3. The theory and calculative method to reveal the cooling efficiency based on temperature versus time measurements with and without water cooling is outlined in Section 4. Statistical analysis in order to reveal the differences in cooling efficiency as a factor of surface roughness is described in Section 5, and the overall results are discussed in Section 6 . The possibility for using the test rig for teaching purposes regarding water droplet boiling regimes and water droplet efficiency is also discussed.

\section{Water Droplet Boiling Regimes}

At ambient pressure, relative humidity below $100 \%$, and temperatures below the boiling point, water droplets evaporate by mass diffusion [5]. Boiling starts when the surface temperature is just above $100{ }^{\circ} \mathrm{C}$, i.e., typically $104{ }^{\circ} \mathrm{C}$ [23]. At this temperature, bubble formation within the saturated fluid starts and results in very slow boiling. The involved mechanism is called nucleate boiling. For a metal surface at $104{ }^{\circ} \mathrm{C}$, the heat flux to a sessile water droplet is limited. Increasing the metal surface temperature increases the heat flux until it reaches a maximum, i.e., the critical heat flux, as shown in Figure 1. Beyond this temperature, increasing the surface temperature reduces the heat flux due to a vapor film partially forming below the droplet. This boiling regime is called transition boiling, and is characterized by violent sizzling and droplet breakup. Further increasing the temperature induces a stable vapor film below the droplet. Thereafter, heat flux from the hot surface to the levitated droplet increases slightly with increasing surface temperature due to the increasing temperature difference between the hot surface and the levitated droplet. The starting temperature for this final boiling regime is called the Leidenfrost temperature [24,25]. The boiling regimes are summarized in Figure 1. 


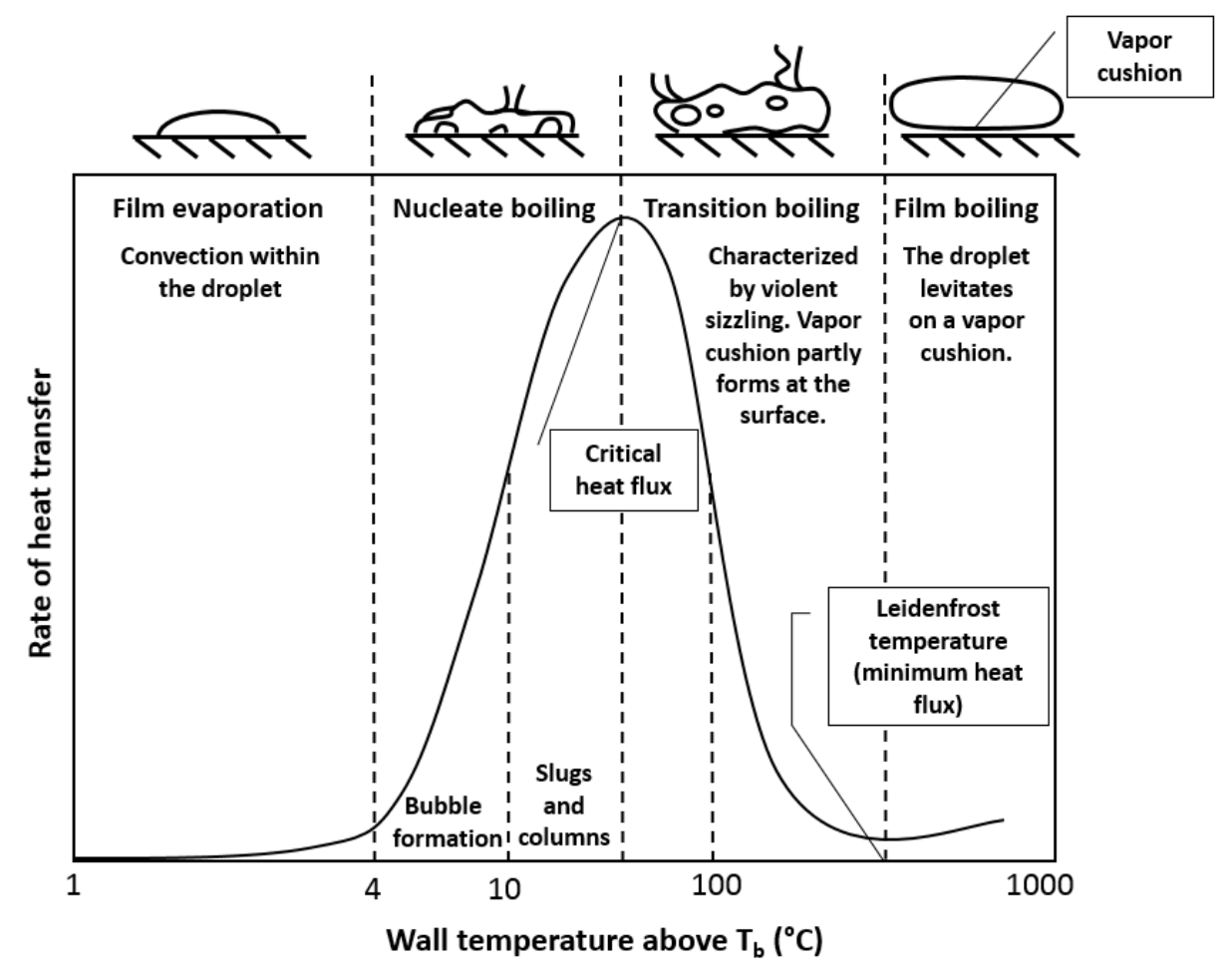

Figure 1. Droplet evaporation/boiling regimes: film evaporation, nucleate boiling, transition boiling, and film boiling. Adapted from [16,17,26].

\section{Experimental Setup}

\subsection{The Discs}

Stainless steel (AISI 316) and aluminum were the selected metals in the present study, with room temperature thermal conductivities of about $15 \mathrm{~W} / \mathrm{m} \cdot \mathrm{K}$ and $150 \mathrm{~W} / \mathrm{m} \cdot \mathrm{K}$, respectively. The arithmetical mean roughness (Ra) used for both discs were Ra 0.4 (polished/smooth surface) and Ra 3, as defined by [27]. Disc sizes of 50-mm diameter and 10-mm thickness (Figure 2) resulted in convenient cooling rates, with and without water cooling. The disc surface color (emissivity) was stabilized by successive complete measurement cycles (explained later in the present chapter) prior to the measurements reported in the present work.

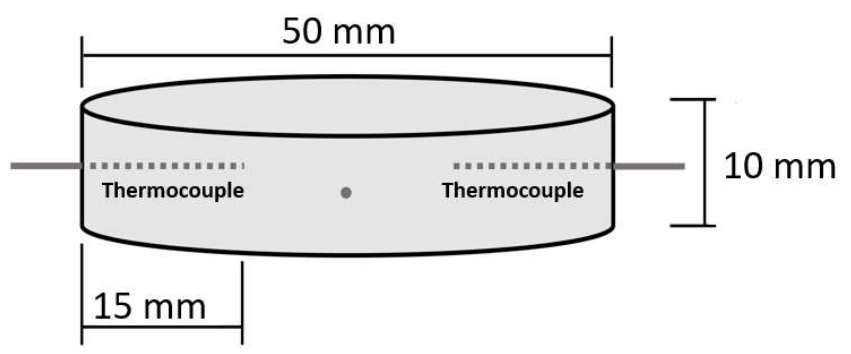

Figure 2. Sketch of metal disc with four inserted type K mantle thermocouples (with 1.6-mm diameter) at $90^{\circ}$ horizontal separation.

\subsection{Disc Positioning and Temperature Measurements}

Ideally, there should be as few heat losses as possible to a fixture, keeping the disc in position. Thin metal rods for supporting the disc were considered. This lead to the decision to combine disc support with temperature recordings, i.e., suspend the disc by four standard 1.6-mm diameter type $\mathrm{K}$ 
(chromel-alumel) mantel thermocouples, as shown in Figure 2. This solution minimized contact between the disc and neighbor objects. The disc was aligned horizontally with a leveler, and heated to about $430^{\circ} \mathrm{C}$ prior to the measurements, as shown in Figure 3. The heater was then removed and the disc was let to cool to $410{ }^{\circ} \mathrm{C}$, ensuring time for the internal temperature gradients to spatially equilibrate prior to each measurement. The experiment as such started when the disc had cooled to temperatures below $410{ }^{\circ} \mathrm{C}$. The disc temperatures were recorded at a frequency of $1 \mathrm{~s}^{-1}$ by a data logger (National instruments NI cDAG-9184, Austin, TX, USA).

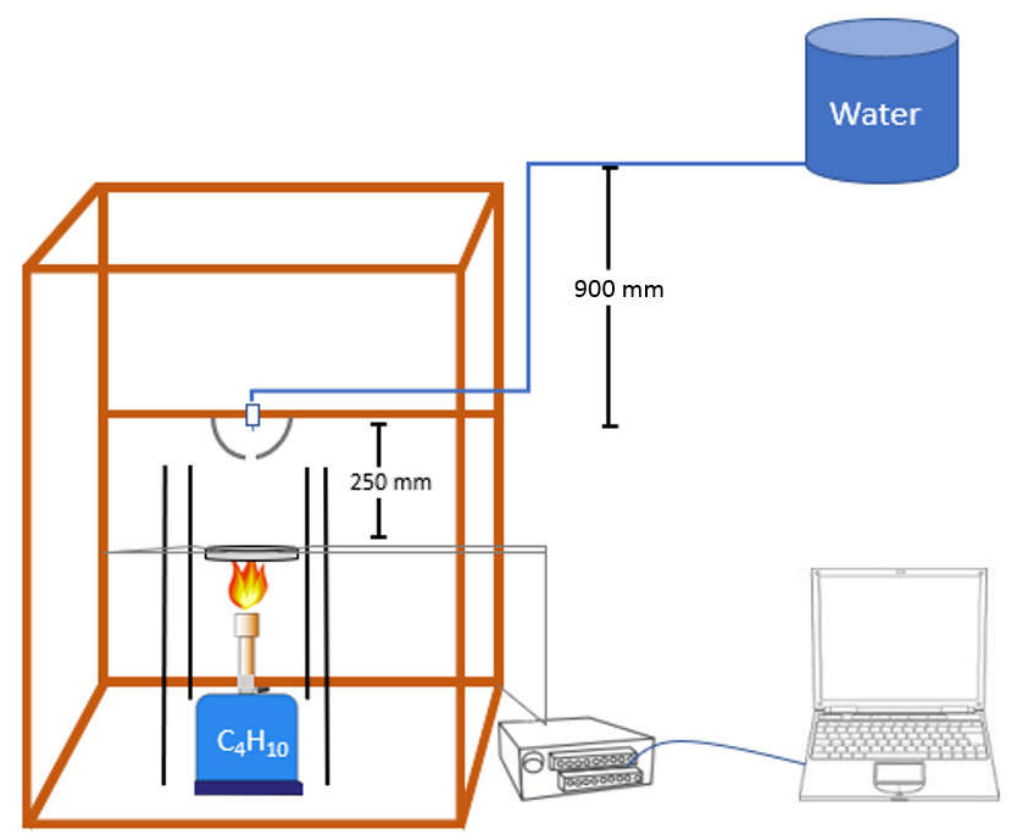

Figure 3. Sketch of the experimental setup (not to scale).

\subsection{Droplet Generation}

Droplets of distilled water were formed at the tip of a medical infusion hypodermic stainless steel needle $\left(25 G^{*} 1\right)$. The arrangement allowed the droplet rate to be regulated in order to obtain a particular flow rate. This simple injection needle system performed well, and represented an ultimate low-cost droplet generator, which has also been used by other researchers [14]. The water droplets detached due to gravity. The chosen impingement height was $25 \mathrm{~cm}$, resulting in an impact velocity of $2.2 \mathrm{~m} / \mathrm{s}$.

Prior to and after each water-cooling measurement, 20 droplets were generated from the arrangement and collected in a small laboratory dish. The mass of the 20 droplets was determined using a balance (AG204DR METTLER TOLEDO, Columbus, OH, USA). Thus, the mass of the individual droplet was determined. Very low variation was observed in the collective mass of succeeding 20 new droplets that were weighed when checking for the reproducibility. Assuming that the droplets were spherical, the droplet diameter was calculated to be $2.4 \mathrm{~mm}$. The mass flow was $0.02 \mathrm{~g} / \mathrm{s}$, i.e., about three droplets/s.

\subsection{Shielding the Setup from Air Currents}

In laboratories, the ventilation currents may disturb experiments significantly. Inspired by Log and Heskestad [28], who studied small-scale fire plumes, the influence of air ventilation was minimized, as well as the influence of personnel movements. This was done by making an open wood frame, $1.1 \mathrm{~m} \times 0.55 \mathrm{~m} \times 1.55 \mathrm{~m}$ height, and covering this frame with a fine mesh screen. A simple roll-up door was made to give access to the interior for setting up experiments, heating the discs, etc. The principle setup is shown in Figure 3. 


\subsection{Metal Disc Dimensions}

It was decided to have a disc diameter that could be quite evenly preheated by a Bunsen burner prior to the experiments without introducing major temperature gradients. If temperature gradients did result from the preheating, they should have time to spatially even out between the preheating and the start of the experiments. A diameter of $50 \mathrm{~mm}$ was found to be convenient in this respect.

The measurements of the disc cooling without, and with, water droplet cooling, relied on exhausting the heat stored in the disc after the preheating. The disc thickness therefore had to be selected such that it allowed for a convenient time period for temperature recordings in both these cases. By trial and error, it was found that a disc thickness of $10 \mathrm{~mm}$ resulted in a proper cooling time both without and with droplets impacting onto the disc.

\section{Determining Cooling Efficiency}

The temperature versus time during disc cooling, with and without impinging water droplets, was recorded for disc temperatures between $85-400{ }^{\circ} \mathrm{C}$. In order to explain the procedure, data from a preliminary aluminum disc cooling experiment is used. The same calculative procedure was used for the final tests presented in Section 6.

\subsection{Water Droplet Cooling Efficiency}

Data from the two reference measurements without applying water droplets, sandwiching the water droplet experiment, were used to calculate the average reference cooling curve. The heat losses were in these cases mainly associated with heat radiation and convective heat losses, with some minor heat loss through the four thermocouples suspending the disc. Between these reference measurements, the droplet-cooling test was done with water droplets applied to the hot metal discs at a constant rate. Typical temperature versus time curves are shown in Figure 4. The respective cooling rates $(d T / d t)$ versus temperature are shown in Figure 5. It is clearly seen that at certain temperatures, the cooling rate is more significant when water droplets were applied to cool the disc. Based on the differences in cooling rates, disc mass, and specific heat, the heat flow to the impinging water droplets was calculated.

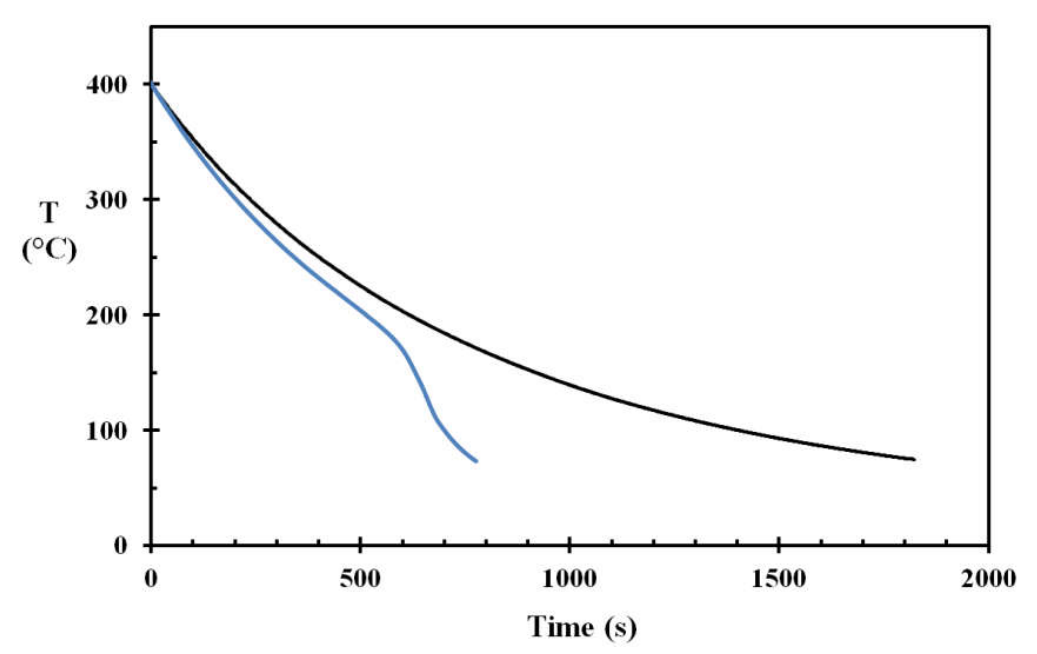

Figure 4. Temperatures of a representative aluminum disc (blue) with 2.4-mm diameter droplets and an application rate of $0.02 \mathrm{~g} / \mathrm{s}$, with the reference temperatures recorded prior to and after the droplet measurements (black). 


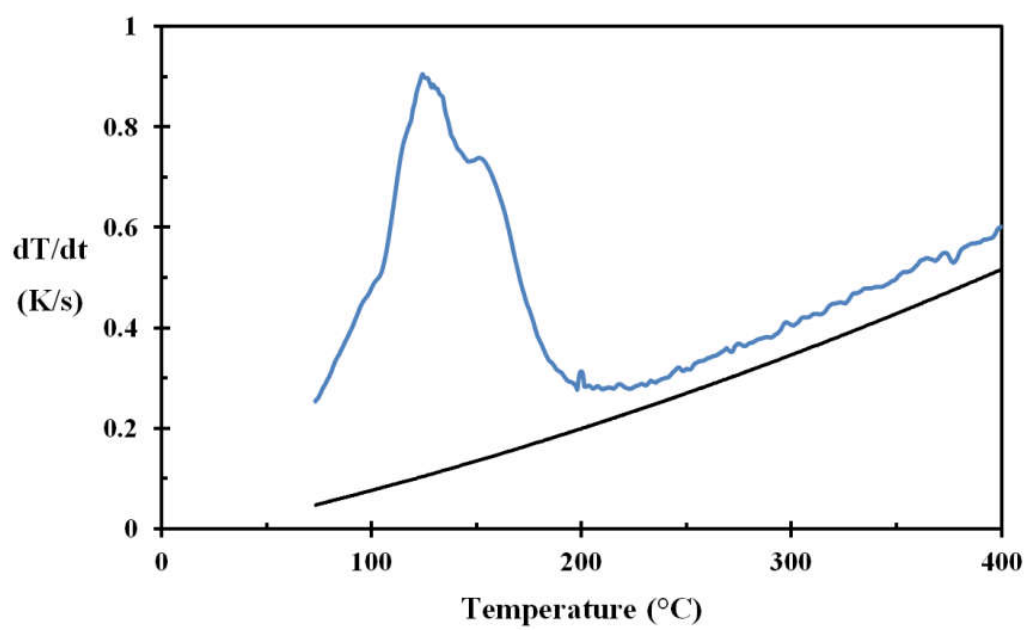

Figure 5. Cooling rate, $d T / d t$, for droplet application (blue) and reference recordings (black) based on temperature data from Figure 4.

Subtracting the temperature versus time derivatives presented in Figure 5 gives the net water droplets' disc-cooling rate, i.e., $\left\{\frac{d T}{d t}\right\}_{\text {Net }}(\mathrm{K} / \mathrm{s})$. Knowing the mass, $m(\mathrm{~kg})$, of the disc, which is in this case $52.9 \mathrm{~g}$, and the specific heat of aluminum as a function of temperature, $C_{\mathrm{P}}(T)(\mathrm{J} / \mathrm{kg} \mathrm{K})$, the water droplet cooling heat flow can be calculated by:

$$
\dot{Q}_{\text {Drops }}(T)=m_{\text {Disc }} \cdot C_{\mathrm{P}}(T) \cdot\left\{\frac{d T}{d t}\right\}_{\mathrm{Net}}(\mathrm{W}),
$$

where the specific heat as a function of temperature is given by the NIST-JANAF Thermochemical Tables [29] as:

$$
C_{\mathrm{P}}(T)=A+B \cdot \tau+C \cdot \tau^{2}+D \cdot \tau^{3}+E / \tau^{2} \quad(\mathrm{~J} / \mathrm{kg} \mathrm{K}),
$$

where $A=28.08920, B=-5.414849, C=8.560423, D=3.427370, E=-0.277375$ and $\tau=T(K) / 1000$. Ignoring the heat flow that is needed to heat the water droplets to $100{ }^{\circ} \mathrm{C}$ and possibly heating the steam above $100^{\circ} \mathrm{C}$, the heat flow that is needed to evaporate the droplets at a rate of $\dot{m}_{\text {Drops }}(\mathrm{kg} / \mathrm{s})$ is given by:

$$
\dot{Q}_{\text {Max }}=\dot{m}_{\text {Drops }} \cdot \Delta H_{\text {vap }}(\mathrm{W}),
$$

where the heat of vaporization at $100{ }^{\circ} \mathrm{C}, \Delta H_{\mathrm{vap}}$, is $2571 \mathrm{~kJ} / \mathrm{kg}$.

The droplet cooling rate as a function of temperature and the droplet cooling potential, $\dot{Q}_{\text {Max }}$, for the test presented in Figure 4 are shown in Figure 6. The temperature of the highest droplet cooling rate, i.e., $124^{\circ} \mathrm{C}$, which corresponds to the critical heat flux, is marked in the figure. It is clearly seen that the cooling capacity does not reach $\dot{Q}_{\text {Max }}$. This was simply caused by some droplets being lost from the disc before evaporating completely.

The relative droplet cooling efficiency, i.e., $\dot{Q}_{\text {Drops }}(T) / \dot{Q}_{\text {Max }}$, is shown in Figure 7. The cooling efficiency relative to heating the steam to the disc temperature is also shown in the figure.

It should be noted that the cooling efficiency at disc temperatures below $100{ }^{\circ} \mathrm{C}$ is quite high. This is a result of droplet wetting, i.e., the remains of previous droplets spread out to make a quite substantial total wet surface area for film evaporation. This was also observed by Pasandideh-Fard et al. [14] in their study of droplets impinging onto metal surfaces at temperatures between $50-120{ }^{\circ} \mathrm{C}$. 


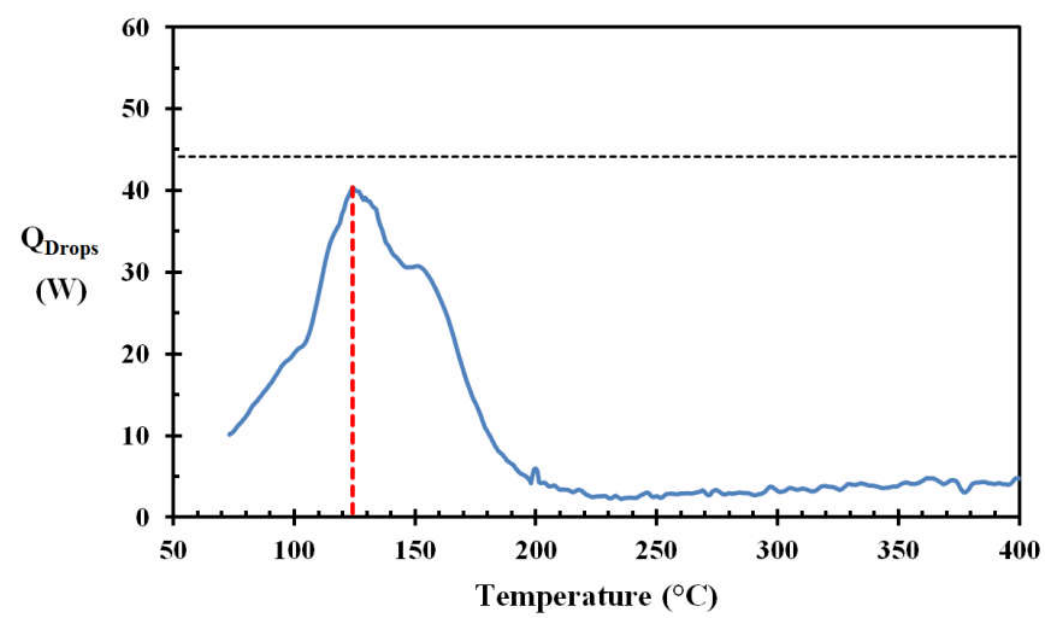

Figure 6. Droplet cooling rate (blue) and heat absorption potential (black dashed line) as a function of temperature. The temperature at the maximum cooling rate is marked (red).

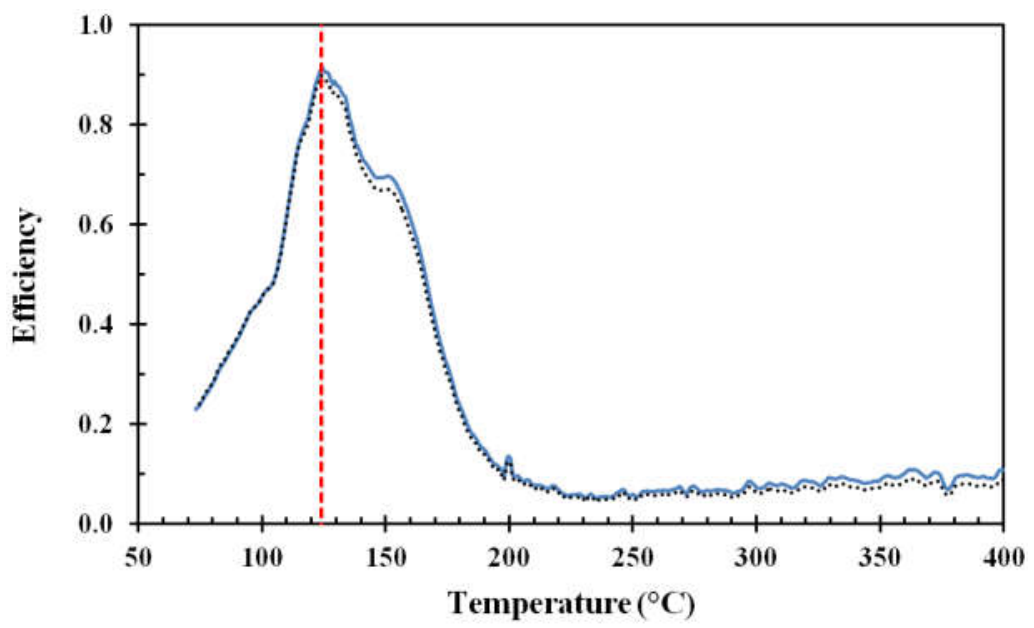

Figure 7. Dimensionless cooling efficiency (blue) and dimensionless cooling efficiency related to the disc temperature (black dashed line). The temperature of the maximum cooling efficiency is marked (red). Data from Figure 6.

\subsection{Confirming Droplet Evaporation Regimes}

When studying Figure 6 in detail, it may be seen that at about $104{ }^{\circ} \mathrm{C}$, there is an abrupt change in the water cooling efficiency versus temperature. This abrupt change corresponds to the transfer from film evaporation below $104{ }^{\circ} \mathrm{C}$ to nucleate boiling above $104{ }^{\circ} \mathrm{C}$. The nucleate boiling regime in this case continued up to about $124^{\circ} \mathrm{C}$, which may be identified as the temperature of critical heat flux, which is also named the boiling crisis [7]. Above about $124^{\circ} \mathrm{C}$, the regime of transition boiling prevails to about $235^{\circ} \mathrm{C}$. Above $235^{\circ} \mathrm{C}$, the droplets experienced film boiling, i.e., the Leidenfrost temperature for the aluminum discs was in this case about $235^{\circ} \mathrm{C}$. This result corresponds well with results reported by other researchers, e.g., the literature review conducted by Bernardin and Mudawar [17] with a reported Leidenfrost temperature for aluminum in the range of $235-265^{\circ} \mathrm{C}$. 


\subsection{Classroom Demonstrations}

The setup, without the wood frame and the fine mesh screen, was moved to a classroom for demonstrating water droplet behavior and cooling efficiency for BSc and MSc students in fire safety engineering. Placed centrally in the room, it allowed for visual and audial observations while the droplets hit the metal plate and cooled the disc. This allowed the students to observe the droplet cooling development through the different evaporation regimes.

It was not within the scope of the present work to formally interview students during the demonstrations. However, they did express increased understanding of water droplet evaporation regimes as a function of metal surface temperature. The potential of very low water cooling efficiency in fire scenarios for temperatures above the Leidenfrost temperature was noted; therefore, it looks like this simple setup may serve both scientific and educational purposes.

\section{Results for Stainless Steel and Aluminum with a Surface Roughness of Ra 0.4 and Ra 3}

Water droplets impinging onto stainless steel and aluminum discs with a surface roughness of Ra 0.4 and Ra 3 were studied in the present work to demonstrate the method for recording water droplet cooling efficiency. A series of five tests with water droplet application, which were sandwiched by two reference measurements as explained earlier, were needed due to the stochastic variations observed, especially close to the temperatures associated with critical boiling.

\subsection{Results of the Stainless Steel Surface Roughness Measurements}

For testing the droplet cooling efficiency for the stainless steel disc, a water application rate of $0.02 \mathrm{~g} / \mathrm{s}$ and droplet size of $2.4 \mathrm{~mm}$, giving a droplet frequency of $3 \mathrm{~s}^{-1}$, were targeted. The droplet speed, which was calculated through the fall height and acceleration of gravity, was $2.2 \mathrm{~m} / \mathrm{s}$. According to Pasandideh-Fard et al. [14], this corresponds well to the droplet speed obtained by photographic methods for similar sized droplets and similar fall heights. The results obtained for surface roughnesses of Ra 0.4 and Ra 3, are shown in Figures 8 and 9, respectively.

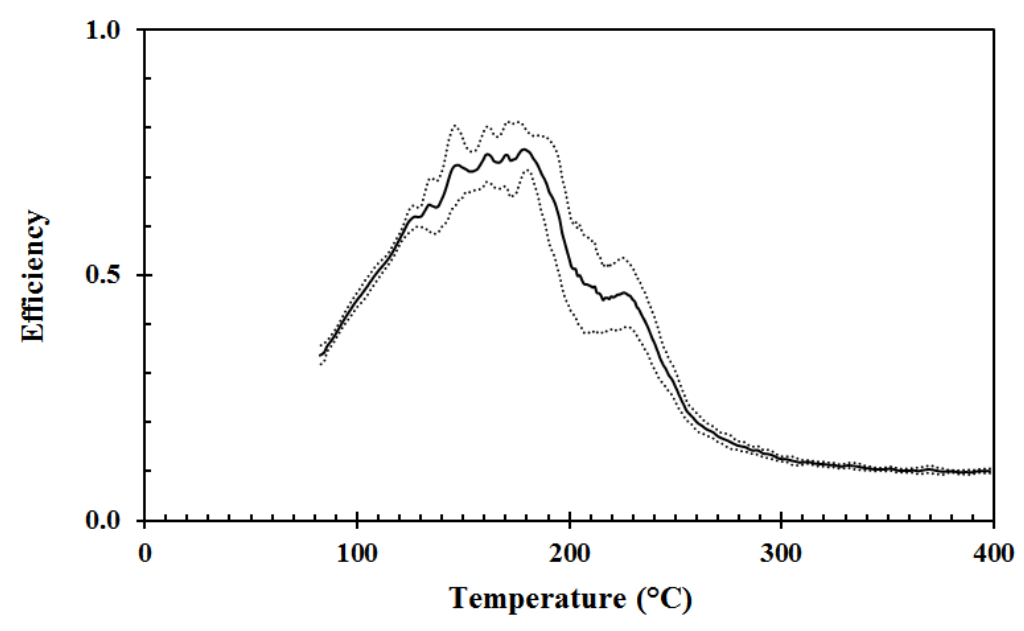

Figure 8. Average cooling efficiency for water droplets impinging onto the stainless steel disc with a surface roughness of Ra 0.4 as a function of temperature (black). The dotted lines represent \pm one standard deviation, respectively.

The standard deviation of the efficiency recorded for the surface roughnesses studied, i.e., Ra 0.4 and Ra 3, is shown in Figure 10 as a function of temperature. The average results for the stainless steel discs with surface roughnesses of Ra 0.4 and Ra 3 are compared in Figure 11. 


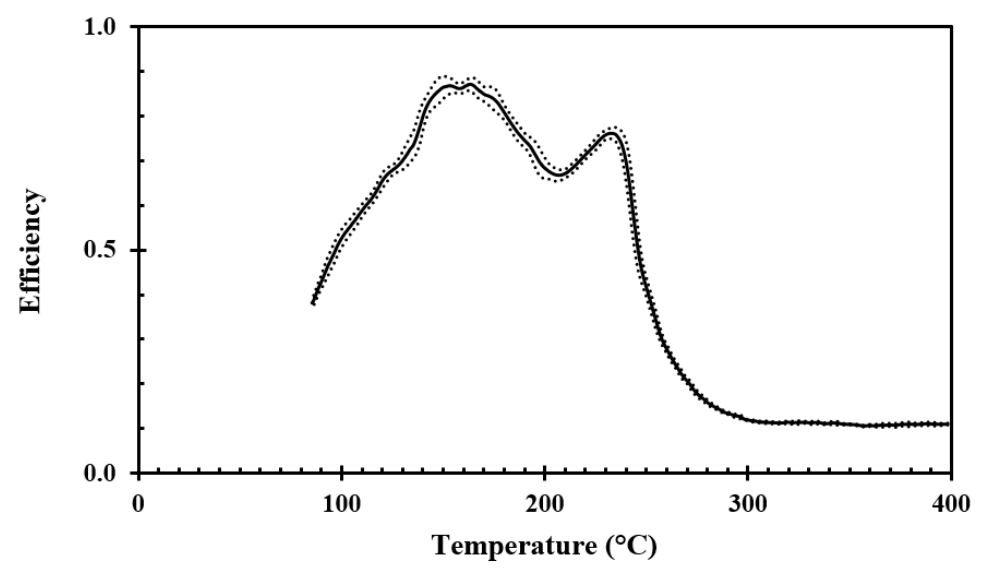

Figure 9. Average cooling efficiency for water droplets impinging onto the stainless steel disc with a surface roughness of Ra 3 as a function of temperature (black). The dotted lines represent \pm one standard deviation, respectively.

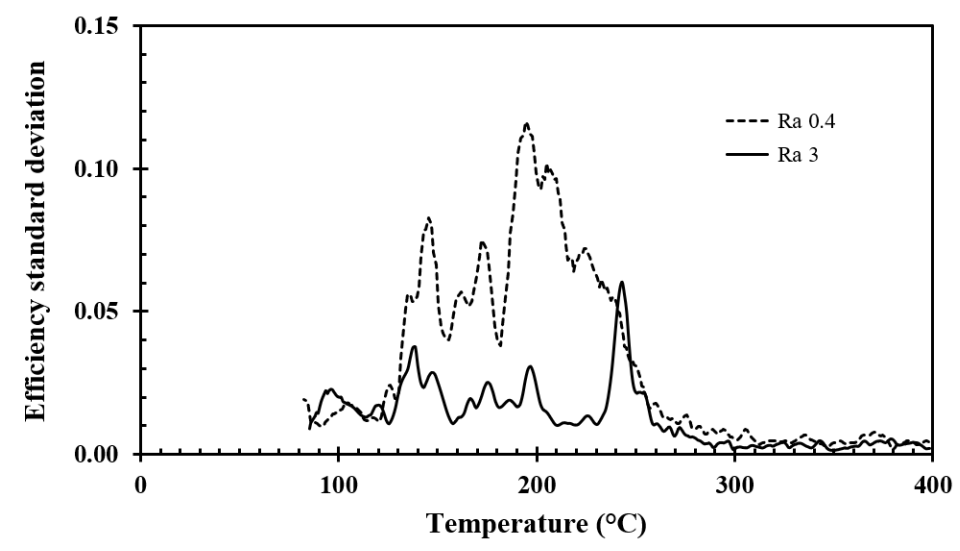

Figure 10. Cooling efficiency standard deviation for water droplets impinging onto the stainless steel disc with surface roughnesses of Ra 0.4 and Ra 3 (marked on the figure).

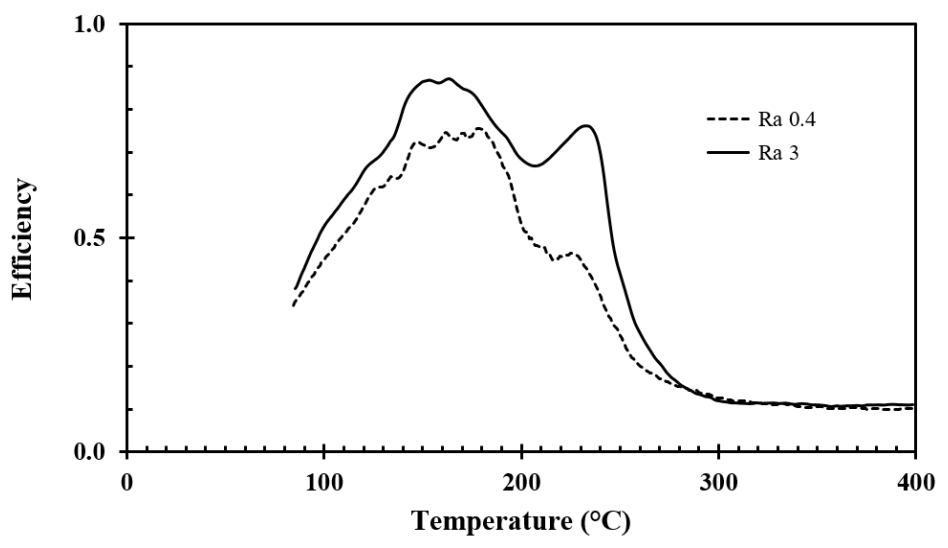

Figure 11. Average cooling efficiency for water droplets impinging onto the stainless steel disc with surface roughnesses of $\mathrm{Ra} 0.4$ and $\mathrm{Ra} 3$ (marked on the figure).

A Student's $t$-test was used to evaluate whether the efficiency recorded for the stainless steel discs with surface roughnesses of $\mathrm{Ra} 0.4$ and Ra 0.3 were significantly different. Checking through the whole temperature range from $85^{\circ} \mathrm{C}$ to $400{ }^{\circ} \mathrm{C}$ and requiring an alpha $<0.05$ indicated that the difference in efficiency as presented in Figure 11 was not statistically valid. 


\subsection{Results of the Aluminum Surface Roughness Measurements}

For recording the droplet cooling efficiency of the aluminum discs, similar water application rates, droplet sizes, droplet frequencies, and droplet speeds as for the stainless steel tests were used, i.e., respectively $0.02 \mathrm{~g} / \mathrm{s}, 2.4 \mathrm{~mm}, 3 \mathrm{~s}^{-1}$, and $2.2 \mathrm{~m} / \mathrm{s}$. The results obtained for surface roughnesses of Ra 0.4 and Ra 3 are shown in Figures 12 and 13, respectively.

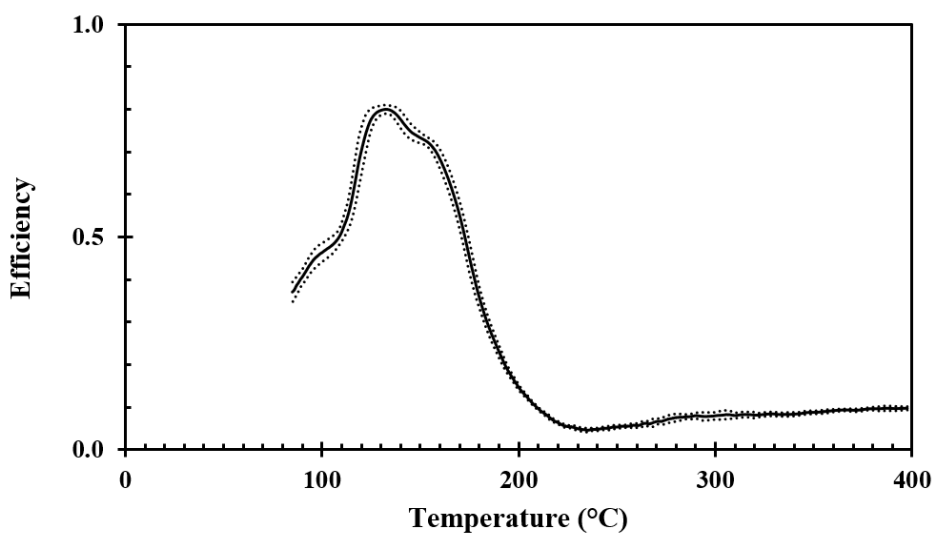

Figure 12. Average cooling efficiency for water droplets impinging onto the aluminum disc with a surface roughness of Ra 0.4 as a function of temperature (black). The dotted lines represent \pm one standard deviation, respectively.

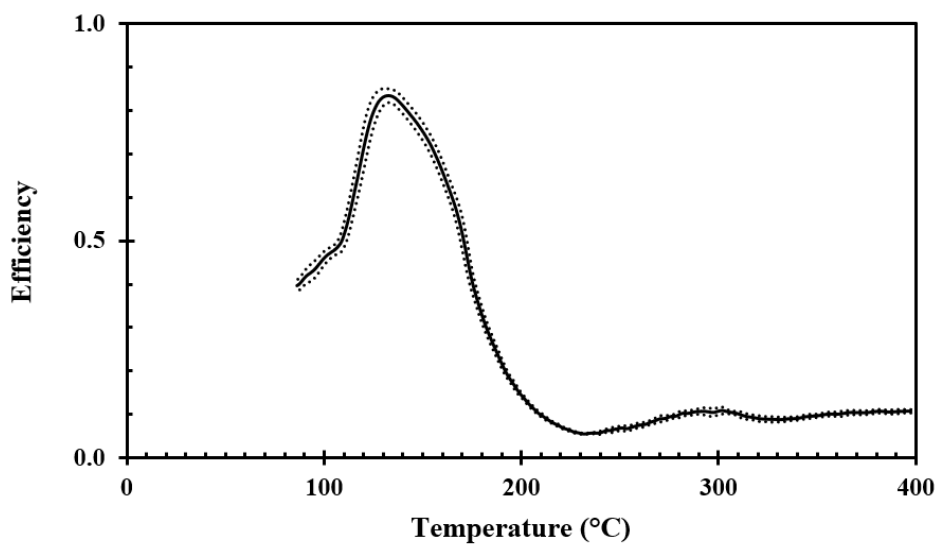

Figure 13. Average cooling efficiency for water droplets impinging onto the aluminum disc with a surface roughness of Ra 3 as a function of temperature (black). The dotted lines represent \pm one standard deviation, respectively.

The standard deviation of the efficiency recorded for the surface roughnesses studied, i.e., Ra 0.4 and Ra 3, is shown in Figure 14 as a function of temperature. The average results for the aluminum discs with surface roughnesses of Ra 0.4 and Ra 3 are compared in Figure 15.

The average results for the aluminum discs with surface roughnesses of Ra 0.4 and Ra 3 are compared in Figure 15.

For aluminum, the Student's $t$-test (alpha $<0.05$ ) showed that the recorded difference in efficiency for surface roughnesses of Ra 0.4 and Ra 3 was significant only for temperatures between $220-310{ }^{\circ} \mathrm{C}$. 


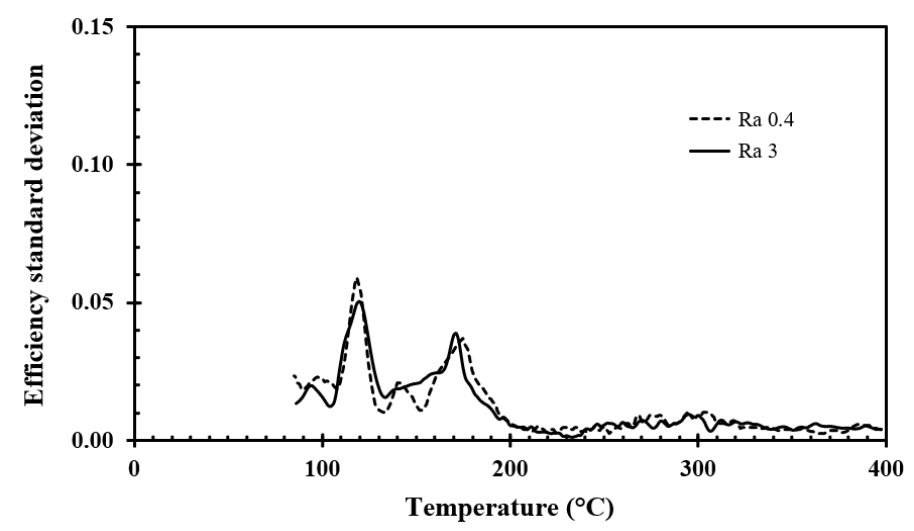

Figure 14. Cooling efficiency standard deviation for water droplets impinging onto the aluminum disc with surface roughnesses of Ra 0.4 and Ra 3 (marked on the figure).

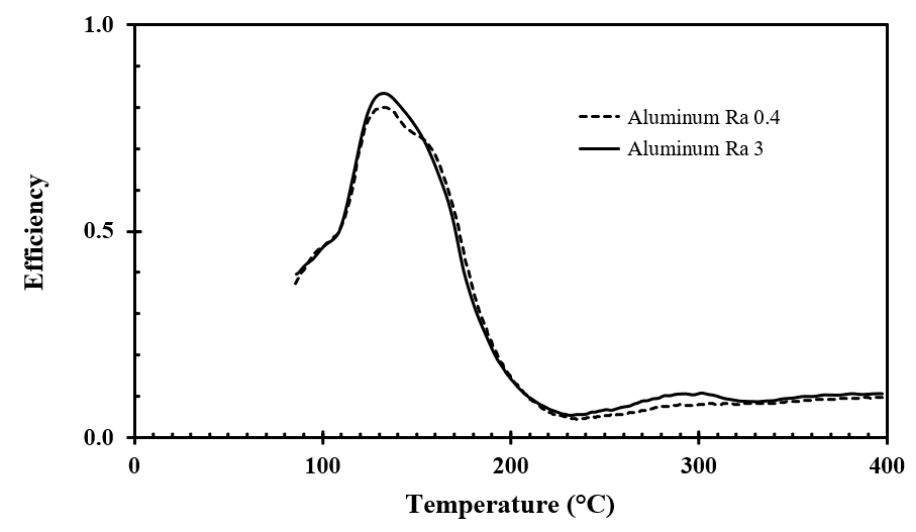

Figure 15. Average cooling efficiency for water droplets impinging onto the aluminum disc with surface roughnesses of Ra 0.4 and Ra 3 (marked on the figure).

\subsection{Comparing the Results for Stainless Steel and Aluminum}

The results for droplets impinging onto the stainless steel and aluminum discs with surface roughnesses of Ra 0.4 and Ra 3 are compared in Figures 16 and 17, respectively. It is clearly seen from these figures that there are quite significant differences in the water droplet efficiency between the respective metals. However, for both of these metals, quite low droplet cooling efficiencies were recorded at temperatures above $300{ }^{\circ} \mathrm{C}$.

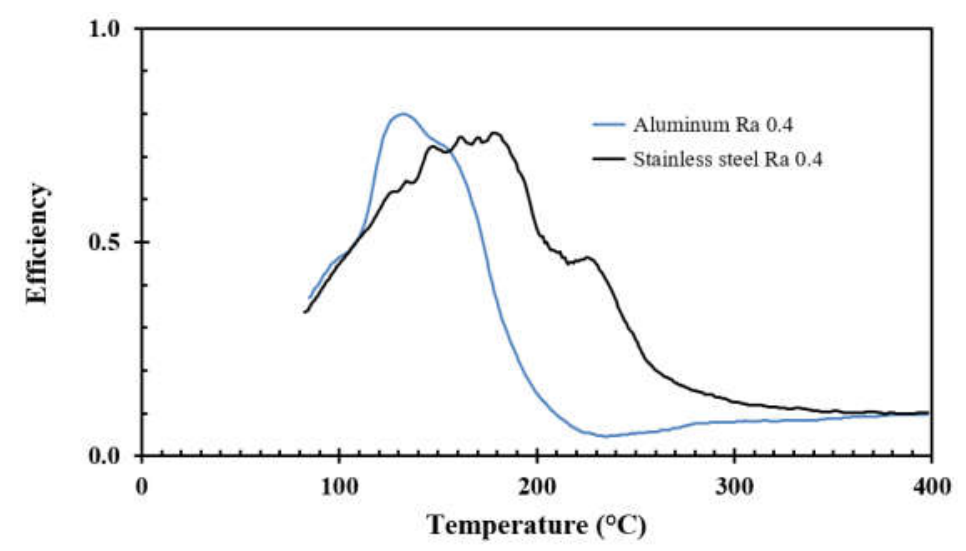

Figure 16. Average cooling efficiency for water droplets impinging onto the stainless steel and aluminum disc (marked on the figure) with a surface roughness of Ra 0.4. 


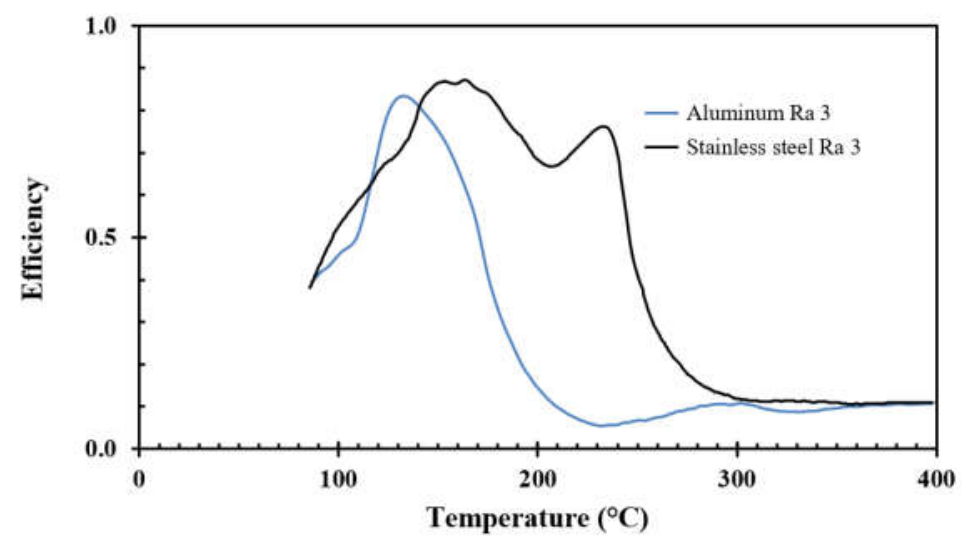

Figure 17. Average cooling efficiency for water droplets impinging onto the stainless steel and aluminum disc (marked on the figure) with a surface roughness of Ra 3.

\subsection{NORSOK Requirements versus Spray Efficiency}

Applying a certain spray flux $\dot{m}^{\prime \prime}\left(\mathrm{kg} / \mathrm{s} \cdot \mathrm{m}^{2}\right)$ with a cooling efficiency of $\xi$ to a hot surface above the boiling point of the liquid, the cooling potential is given by:

$$
\dot{Q}_{\text {Cool }}^{\prime \prime}=\xi \cdot \dot{m}^{\prime \prime} \cdot \Delta H_{\text {vap }}\left(\mathrm{W} / \mathrm{m}^{2}\right)
$$

Assuming that at e.g., $400^{\circ} \mathrm{C}$ the cooling efficiency is about 0.10, a NORSOK [19] spray application rate of $10 \mathrm{~L} / \mathrm{min} \cdot \mathrm{m}^{2}$, i.e., $0.167 \mathrm{~kg} / \mathrm{s} \cdot \mathrm{m}^{2}$, would be able to withdraw $43 \mathrm{~kW} / \mathrm{m}^{2}$ from the fire exposed surface. This is much lower than the heat flux from an industrial fire to an exposed object at $400{ }^{\circ} \mathrm{C}$. Dependent on the fire scenario, this object may experience net heat flux levels between $200-350 \mathrm{~kW} / \mathrm{m}^{2}$.

The low cooling efficiency experienced above the Leidenfrost temperature explains why it is very important to activate deluge systems early in order to cool pressurized pipes and process equipment in order to keep the temperature development under control. If not, the water spray may have limited effects, and may not be able to prevent hot spot formation and a possible loss of containment, possibly resulting in a severely increased fire scenario.

\subsection{Error Analysis}

It was not possible to get exactly the same water application rate and exactly the same droplet diameters for each measurement series with the current setup. However, the standard deviation was within $2 \%$ for the water application rate and within $\pm 1 \%$ for the droplet diameter. The $25.0-\mathrm{cm}$ elevation for droplet acceleration was measured to be within $1 \mathrm{~mm}$, i.e., representing less than $1 \%$ error in the droplet speed. Given the rather large standard deviations observed for the stainless steel discs, the droplet diameter, application rate, and droplet speed can be considered sufficiently constant for comparing the results from the different measurement series.

The discs were aligned horizontally to within $0.5^{\circ}$ before each measurement series. However, there may be some slight misalignment during the heating and cooling cycles. This may to some extent influence the results. However, misalignment larger than $1^{\circ}$ after the completion of each measurement series was not discovered. It is therefore reasonable to assume that the differences recorded in the water droplet cooling efficiencies were due to the different metals used, and for some temperature regions, the surface roughness.

The reason for the larger standard deviation in the recorded efficiency for stainless steel compared with aluminum may be due to the lower thermal conductivity/diffusivity of the stainless steel. When two consecutive droplets hit exactly the same spot, which ideally was the goal, the stainless steel surface did not recover thermally as much between each droplet impact as was the case for the aluminum discs. If a droplet then hit just off the impact point of the previous droplets, it would be 
partly exposed to a higher surface temperature. The one order of magnitude higher heat transport properties of aluminum better evened out the cooling impacts by the previous droplets. When the temperature gradients for aluminum were less steep, it did not make much difference whether the subsequent droplets hit the same location, or were slightly off from that location. Therefore, it was expected that the standard deviations experienced for the droplets impacting onto the aluminum discs would be lower than for the stainless steel discs.

\section{Discussion}

A method for measuring the cooling efficiency of water droplets impinging onto hot metal surfaces was developed. The test apparatus was described, measurements were performed on stainless steel and aluminum discs, and the recordings were processed to reveal the cooling efficiency in the temperature range between $85-400{ }^{\circ} \mathrm{C}$. It was also investigated whether the method can reveal any differences in the cooling efficiency as a function of the surface roughness. Therefore, the 50-mm diameter and 10-mm thick metal discs tested were prepared with roughnesses of Ra 0.4 and Ra 3 for both materials. The test setup was validated by droplets (with a 2.4-mm diameter) generated by the acceleration of gravity from a hypodermic injection needle impacting onto the disc center at a speed of $2.2 \mathrm{~m} / \mathrm{s}$ and a rate of $0.02 \mathrm{~g} / \mathrm{s}$, i.e., about three droplets per second.

The horizontally aligned disc was suspended by four thermocouples penetrating the disc $15-\mathrm{mm}$ radially, along the horizontal symmetry plan. This solution minimized contact between the disc and other objects, and allowed for recording the disc temperature during the cooling phase with and without cooling the disc by water droplets. Several researchers placed a thermocouple junction either flush with or $0.5 \mathrm{~mm}$ below the droplets' impact point [11,14]. This allowed them to record the surface temperature at the impact point. The thermocouple then induces a disturbance in the metal exactly at the point where the droplets hit the surface. The present method aimed at recording the temperature within the metal disc, with four symmetrically located thermocouples giving minimal disturbances to the droplet impact point. This gave a better representation of the water-cooling process of metallic objects, as such, during the cooling process. The tradeoff by losing information about the impact point surface temperature was thus outweighed by the possibility for better determining the water droplet cooling efficiency.

For the aluminum discs, the water droplet cooling efficiency associated with the critical heat flux, i.e., at about $125{ }^{\circ} \mathrm{C}$, was in the range of $80 \%$ to $85 \%$. The lowest water droplet cooling efficiency, i.e., in the range of $6 \%$ to $10 \%$, was observed at a disc temperature of about $230{ }^{\circ} \mathrm{C}$. Since this temperature was associated with a minimum in the cooling efficiency, it may be defined as the Leidenfrost temperature. The cooling efficiency then slightly increased with increasing temperature up to $400{ }^{\circ} \mathrm{C}$ due to the increasing temperature difference between the disc surface and the evaporating levitated droplet.

For stainless steel discs, at the recorded temperatures associated with the critical heat flux, i.e., about $150{ }^{\circ} \mathrm{C}$ to $180{ }^{\circ} \mathrm{C}$, the droplet cooling efficiency was found to be in the range of $70 \%$ to $80 \%$. The reason for this slightly lower maximum cooling efficiency compared to aluminum is likely due to the differences in thermal properties, i.e., a thermal conductivity of $150 \mathrm{~W} / \mathrm{mK}$ for aluminum versus $15 \mathrm{~W} / \mathrm{mK}$ for stainless steel.

For aluminum, the surface temperatures recovered more between each droplet impact compared to stainless steel, i.e., the impingement point was more thermally disturbed by the time the next droplet hit the stainless steel surface. Small variations in droplet impact point and droplet movements just after impact likely explained the higher standard deviations in the recorded efficiency for the stainless steel discs. Large standard deviations in measurements from the temperature regions near the temperature associated with the critical heat flux are also reported in other studies [16], although those researchers did not focus on droplet cooling efficiency.

Clear differences in cooling efficiency were demonstrated between aluminum and stainless steel (same roughness for both metal disc surfaces). It was more challenging to reveal the differences in cooling efficiency within the same material, i.e., for the two different roughnesses studied (Ra 0.4 
and Ra 3). The Student's t-test (alpha < 0.05) was applied to indicate whether there were statistically significant differences between the water droplet cooling efficiency obtained for Ra 0.4 and Ra 3 . The observed water droplet cooling efficiency differences for Ra 0.4 and Ra 3 were for the aluminum discs significant (alpha $>0.05$ ) only for temperatures between $220-310{ }^{\circ} \mathrm{C}$, where the higher surface roughness ( $\mathrm{Ra} 3$ ) gave a slightly higher cooling efficiency. This may be explained by the better possibilities for the water vapor generated to escape through the crevices below the droplet, i.e., resulting in less distance between the droplet and the aluminum surface peaks.

Due to the larger standard deviation in cooling efficiency observed for the stainless steel discs, any observed differences between the surface roughnesses of Ra 0.4 and Ra 3 were not statistically significant, i.e., Student's $t$-test alpha $>0.05$. Indeed, for temperatures above $265{ }^{\circ} \mathrm{C}$, the cooling efficiency was practically equal for stainless steel surface roughnesses of Ra 0.4 and Ra 3 . It is more difficult to explain this observation. However, many parameters do control the heat and mass transfer in the film boiling regime [7]. For stainless steel, the influence of crevices and peaks may be less prominent due to the heat transfer capacity being 10 times lower than that of similar peaks on the aluminum surface.

The results indicate that the application of fire water early in a fire scenario is very important, i.e., while the water cooling will likely be most efficient and thereby may prevent further temperature increase past the temperature associated with a boiling crisis. Upon reaching the film boiling regime, the cooling efficiency of the stainless steel discs was shown to become as low as about $12 \%$ to $14 \%$ due to the stable vapor film below the droplet. Even with application of the recommended $10 \mathrm{~L} / \mathrm{min} \cdot \mathrm{m}^{2}$, i.e., $0.167 \mathrm{~kg} / \mathrm{s} \cdot \mathrm{m}^{2}$ recommended by NORSOK [19], the spray would only be able to withdraw $50-60 \mathrm{~kW} / \mathrm{m}^{2}$ from the fire exposed surface. This is significantly lower than the heat flux that objects may be exposed to in industrial fires, i.e., $250 \mathrm{~kW} / \mathrm{m}^{2}$ to $350 \mathrm{~kW} / \mathrm{m}^{2}$. This is a paradox for fire safety engineering.

The literature study did not reveal research papers investigating the absolute cooling efficiency of water droplets applied to hot metal surfaces of e.g., 10-mm wall thickness. Therefore, the present work may be the first to attempt quantifying this for objects of representative wall thicknesses. However, it should be noted that a variety of metal qualities are used in process plants, and that the present study is limited to horizontally aligned stainless steel discs of $10-\mathrm{mm}$ thickness. In the process industry, equipment and pipe work may also be thermally insulated and shielded by stainless steel cladding. Such cladding, with thicknesses of $0.5 \mathrm{~mm}$ or $0.7 \mathrm{~mm}$, is unfortunately too thin to be analyzed by the presented setup.

Omitting the fine mesh screen and moving the core setup to the classroom for demonstrating water droplet behavior and cooling efficiency worked well for demonstrating the mentioned physical phenomena to BSc and MSc students in fire safety engineering. The students expressed an increased understanding of water droplets' cooling efficiency as a function of substrate temperature. The potential of very low water cooling efficiency in fire scenarios was noted. Therefore, it can be concluded that this simple setup serves both scientific and educational purposes.

Author Contributions: T.L. conceived the concept. J.S.B. and M.-M.M. designed the experimental setup. J.S.B. performed the experiments; J.S.B. and T.L. analyzed the data; M.-M.M. contributed materials and equipment and Ø.F. contributed as an advisor throughout; J.S.B., M.-M.M. and T.L. wrote the paper.

Funding: J.S.B. was supported by the Norwegian Research Council, Grant No. 257901 and Gassco Inc., Norway, Grant No. PO 4500024195.

Acknowledgments: The authors would like to acknowledge technical support from G. Kleppe. Support in realizing the project from Gunnar Birkeland, Uni Research Polytec, and Terje Øverland and Kjell Erik Kleveland, PDS Protek is also appreciated. The suggestions from the anonymous reviewers for improving the manuscript are highly appreciated.

Conflicts of Interest: The authors declare no conflict of interest. 


\section{References}

1. Chegini, G.R.; Ghobadian, B. Spray Dryer Parameters for Fruit Juice Drying. World J. Agric. Sci. 2007, 3, 230-236.

2. Dugas, V.; Broutin, J.; Souteyrand, E. Droplet evaporation study applied to DNA chip manufacturing. Langmuir 2005, 21, 9130-9136. [CrossRef] [PubMed]

3. Deegan, R.D.; Bakajin, O.; Dupont, T.F.; Huber, G.; Nagel, S.R.; Witten, T.A. Capillary flow as the cause of ring stains from dried liquid drops. Nature 1997, 389, 827-829. [CrossRef]

4. Lopes, M.-C.; Bonaccurso, E.; Gambaryan-Roisman, T.; Stephan, P. Influence of the substrate thermal properties on sessile droplet evaporation: Effect of transient heat transport. Colloids Surf. A Physicochem. Eng. Asp. 2013, 432, 64-70. [CrossRef]

5. Log, T. Water Droplets Evaporating on Horizontal Semi-infinite Solids at Room Temperature. Appl. Therm. Eng. 2016, 93, 214-222. [CrossRef]

6. Girard, F.; Antoni, M.; Faure, S.; Steinchen, A. Influence of heating temperature and relative humidity in the evaporation of pinned droplets. Colloids Surf. A Physicochem. Eng. Asp. 2008, 323, 36-49. [CrossRef]

7. Misyura, S.Y. The effect of weber number, droplet sizes and wall roughness on crisis of droplet boiling. Exp. Therm. Fluid Sci. 2017, 84, 190-198. [CrossRef]

8. Nguyen, T.; Nguyen, A.; Hampton, M.; Xu, Z.; Huang, L.; Rudolph, V. Theoretical and experimental analysis of droplet evaporation on solid surfaces. Chem. Eng. Sci. 2013, 69, 522-529. [CrossRef]

9. Zhou, X.; Zhou, B.; Jin, X. Study of fire-extinguishing performance of portable water-mist fire extinguisher in historical buildings. J. Cult. Herit. 2010, 11, 392-397.

10. Bhatt, N.H.; Pati, A.R.; Kumar, A.; Behera, A.; Munshi, B.; Mohapatra, S.S. High mass flux spray cooling with additives of low specific heat and surface tension: A novel process to enhance the heat removal rate. Appl. Therm. Eng. 2017, 120, 537-548. [CrossRef]

11. Fukuda, S.; Kohno, M.; Tagashira, K.; Ishihara, N.; Hidaka, S.; Takata, Y. Behavior of small droplet impinging on a hot surface. Heat Transf. Eng. 2014, 35, 204-211. [CrossRef]

12. Lee, C.H.; Kim, D.Y.; Kim, H.D.; Kim, K.C. Dynamic behavior and micro-explosion characteristics of impinging droplets on a high-temperature surface. J. Vis. 2015, 18, 59-70. [CrossRef]

13. Gradeck, M.; Seiler, N.; Ruyer, P.; Maillet, D. Heat Transfer for Leidenfrost drops bouncing onto a hot surface. Exp. Therm. Fluid Sci. 2013, 47, 14-25. [CrossRef]

14. Pasandideh-Fard, M.; Aziz, S.D.; Chandra, S.; Mostaghimi, J. Cooling effectiveness of a water droplet impinging on a hot surface. Int. J. Heat Fluid Flow 2001, 22, 201-210. [CrossRef]

15. Birdi, K.S.; Vu, D.T.; Winter, A. A study of the evaporation rates of small water drop placed on a solid surface. J. Phys. Chem. 1989, 93, 3702-3703. [CrossRef]

16. Liang, G.; Mudawar, I. Review of drop impact on heated walls. Int. J. Heat Mass Transf. 2017, 106, $103-126$. [CrossRef]

17. Bernardin, J.D.; Mudawar, I. The Leidenfrost point: Experimental Study and Assessment of Existing Models. J. Heat Transf. 1999, 121, 894-903. [CrossRef]

18. Sawyer, M.L.; Jeter, M.S.; Abdel-Khalik, S.I. A critical heat flux correlation for droplet impact cooling. Int. J. Heat Mass Transf. 1997, 40, 2123-2131. [CrossRef]

19. Norsk Standard. Technical Safety, NORSOK Standard, 4th ed.; Standard no. S-001; Norsk Standard: Lysaker, Norway, 2008; 62p.

20. Kazemi, Z. Droplet Impaction on Solid Surfaces Exposed to Impinging Jet Fires. Ph.D. Dissertation, Norwegian University of Science and Technology, Trondheim, Norway, 2006.

21. Drange, L.A. A Study of Selected Problems Related to Accidental Process Fires. Ph.D. Dissertation, University of Bergen, Bergen, Norway, 2011.

22. Opstad, S.A.; Wighus, R. Droplet Sizes from Deluge Nozzles; NBL F09117; SINTEF Report: Trondheim, Norway, 2009.

23. Chang, H. The myth of the boiling point. Sci. Prog. 2008, 91, 219-240. [CrossRef] [PubMed]

24. Leidenfrost, J.G. De Aquae Communes Nonnullis Qualitatibus Tractatus; Ovenius: Duisburg, Germany, 1756.

25. Leidenfrost, J.G. On the Fixation of Water in Diverse Fire. Int. J. Heat Mass Transf. 1966, 9, $1153-1166$. [CrossRef] 
26. Faghri, A.; Zhang, Y.; Howell, J.R. Advanced Heat and Mass Transfer; Global Digital Press: Columbia, MO, USA, 2010; ISBN 978-0-9842760-0-4.

27. International Standard. Geometrical Product Specifications (GPS)—Surface Texture: Profile Method-Terms, Definitions and Surface Texture Parameters; ISO 4287; ISO: Geneva, Switzerland, 1997; 25p.

28. Log, T.; Heskestad, G. Temperatures of Restricted Turbulent Fire Plumes. Fire Saf. J. 1998, 31, $101-115$. [CrossRef]

29. Chase, M.W. NIST-JANAF Themochemical Tables, 4th ed.; American Institute of Physics: College Park, MA, USA, 1998. Available online: https:/ / srd.nist.gov/JPCRD/jpcrdM9.pdf (accessed on 5 February 2017). 